\title{
X-Ray Cross Complementing Group
}

National Cancer Institute

\section{Source}

National Cancer Institute. X-Ray Cross Complementing Group. NCI Thesaurus. Code C18297.

A genetic complementation group for X-ray sensitivity. 